\title{
Youth and Well-Being: A South African Case Study
}

\author{
Monde Makiwane $\cdot$ Stella Kwizera
}

Accepted: 10 June 2008/Published online: 22 July 2008

(C) The Author(s) 2008

\begin{abstract}
This paper was a result of an analysis from various data sources with a purpose to develop a better understanding of the level of socio-economic well being of young people in South Africa. Such understanding is aimed at enabling government to plan and implement well-structured and integrated development programmes that are relevant to the socio-economic needs of the youth and that will enable them to fully participate in all aspects of society. Two main sources of data were used for this analysis. The first is the Status of the Youth (SYR) data set. The second data set used in this study is the South African Social Attitudes Survey (SASAS) which is a national representative sample of 5,000 households. The study shows that the quality of life among majority of young people remains low, reflecting the historical racial cleavages of South African society. This is mainly due to the emergence of the AIDS pandemic in South Africa, and the fact that many young people remain outside the labour market.
\end{abstract}

Keywords Youth · Well-being · South Africa - Quality of life · Labour market · Mortality $\cdot$ Fertility $\cdot$ Poverty

\section{Introduction and Background}

This paper reports on a study conducted to develop a better understanding of the level of socio-economic well-being of young people in South Africa. The study establishes precise profiles of the socio-economic and demographic characteristics of youth in South Africa, covering such specifically selected life domains, which, in complex interrelationships, combine to impact on their well-being socially and economically (although such relationships are not assessed in the study). Domains selected include: education and skills

M. Makiwane $(\bowtie)$

Child Youth, Family and Social Development, Human Science Research Council, Pretoria,

South Africa

e-mail: mmakiwane@hsrc.ac.za

S. Kwizera

Department of Sociology, Walter Sisulu University, Mthatha, South Africa 
development, employment, financial independence, access to basic services and health care, capacity to own basic household amenities, poverty, fertility and mortality levels, and satisfaction with life in general.

The broader aim was to influence government in planning and implementation of wellstructured and integrated development programmes relevant to the socio-economic needs of youth to enable them to participate in all aspects of society. Such a motivation arose as a result of a general concern in the country over the well-being of young people in the country. The Department of Social Development (DSD), for one, has drawn the country's attention to the recognition that past policies have had a detrimental impact on the present generation of youth and this has affected their ability to live fulfilling lives, realise their potential, and participate meaningfully in the social, political and economic activities of the society. An appropriate response to the special needs of young people as mentioned above, was, therefore, necessary to establish the precise profiles of the socio-economic and demographic characteristics of youth as mentioned above.

Specific objectives of the study were to provide comprehensive information on the demographic, social and economic circumstances of young people using special age bands and with reference to race.

In particular, the study:

- Describes the employment status and financial independence of young people;

- Assesses young people's level of and access to education and skills development;

- Assesses their poverty, fertility and mortality levels;

- Provides a brief commentary on young people's access to housing, water, electricity and other household amenities, and healthcare;

- Measures their satisfaction with life in general.

Although various definitions of youth are used in South Africa, the definition adopted by the National Youth Act of 1996 was used for this study. The act defines youth as persons in the age group 14-35 years of age. This group does not comprise a homogeneous entity and it is, therefore, important to disaggregate the analysis according to, race, gender, urban/ rural status, and 5 year age group. As 15 is the age at which children are formally permitted to enter the labour market in South Africa, this age was used as the lowest level for discussion on employment and unemployment.

\subsection{Sources of Data}

Two main sources of data were used for this analysis. The first is the Status of the Youth (SYR) data set. This is national, representative youth data collected in 2003. The SYR data set is a self-weighting sample design, based on the most recent available data from Statistics South Africa (STATSSA). Thus, the major reporting domains of the sample were drawn so that they are proportional to that of Census 2001. The original sample design was 3,500 individuals. Minority population, namely Whites and Indian groups, were slightly over-sampled in the study but, as this is so slight, it does not change the self-weighting nature of the sample. Most of the analysis in this study is based on this data set.

The second data set used in this study is the South African Social Attitudes Survey (SASAS) which is a national, representative sample of 5,000 households visited in 2007. The survey was designed to yield a representative sample of adults aged 16 and older, with no upper age limit, regardless of their nationality or citizenship. The sample was chosen from the 2001 census sample frame, and was stratified by the socio-demographic domains 
of province, geographical sub-type and the four major race groups. The two measures of Quality of Life (QoL) drawn from the study were analysed for young persons between the ages 18 to 34 years, so as to concur with the age group contained in the Status of the Youth Data set.

Three measures of QoL of young people were compiled from the SASAS data. Quality of life levels in this study were determined by using three measures, which were answers to the following questions; "Taking all things together, how happy are you?" The scaling of the answer ranges from 1 for 'very happy', to 5 for 'very unhappy'. The second question asks "How satisfied are you with your life these days?". The answers to the question ranges from one for 'very satisfied' to five for 'very unsatisfied'. The third question is related to Living Standard Measure, which gives a score for number goods and services young people have in their household. The score ranges from ten for a young person staying in a household with most goods and services, and therefore living a comfortable lifestyle, to 1 on the opposite side of the scale.

\subsection{Sources of Youth Mortality Data}

STATSSA published data on adult mortality for the years 1997-2004. The youth mortality data presented below was extracted from this series (STATSSA 2006b). The mortality has been estimated from the Death Notification Forms. Denominators used to calculate death rates were from the Mid-year estimates that are released annually by STATSSA. The death rates have been adjusted for incompleteness of registration system in South Africa.

\section{Background Literature and Findings}

The findings reported below are in part from a review of existing literature, but in the majority, are based on the data from the Status of the Youth study. This study was conceptualised and carried out by a team of researchers which included the authors.

\subsection{Youth Demographics in South Africa}

The demographic share of young people, aged 14-35 years in South Africa is currently estimated at $37 \%$. This is expected to peak between 2000 and 2010 but will enjoy a long plateau at these high levels for the next 20-30 years (World Bank 2006). Coined as the 'demographic dividend', this expansion of the working age population, with fewer children and elderly to support, presents a window of opportunity for rapid human capital development and economic growth (World Bank 2006).

This opportunity provided by the above demographic dividend is, however, time bound, in that, the growth in the ageing population will eventually close this window, as is currently the case in most developed countries. It cannot be overemphasised that the development benefits to be accrued, as is always the case, are at their highest during childhood and youth through investments in health, education and job creation.

Therefore, to take advantage of this dividend, especially in a knowledge-based society, where human capital is the trading currency, sound policies, institutions and programmes are required. Youth represents the developmental phase where critical decisions are taken on the key life transitions including; continuing education, entering work, adopting healthy lifestyles, starting a family and participating in society. These decisions have long-term 
impacts not only for young people but also for their families, communities and the economy. Ten to fifteen years of research on youth in South Africa tells us that young people's experiences are diverse and at times paradoxical (Morrow et al. 2005).

For example, data from the SYR data demonstrates that youth education has expanded especially for African youth and for women, but that unemployment has worsened. While more jobs have been created in the formal economy, these have not necessarily benefited young people (Richter et al. 2005).

The country has made progress in institutionalising youth development, as a 'precondition for systematic advancement', but concerns about the marginalisation of youth, first voiced in the late 1980s and early 1990s, still persist in the form of unemployment, poverty, unequal and for the most part, poor education systems, family and community disintegration, and exposure to crime and violence (Morrow et al. 2005, p. 3). Some new issues have also emerged. For example, HIV/AIDS is clearly at the forefront on the list of challenges facing youth and, the seemingly political and civic disengagement are also a cause for concern (Morrow et al. 2005).

Analysis of South African mid year population estimates in 2005 shows that young people constituted 37\% of the population, a decline from the 2001 estimate of $40.5 \%$. Young people are generally a mobile sector of the population often moving for education, and better social and economic opportunities. As is the case in the general population, large numbers of young people, particularly African and Coloured youth, are migrating from rural to urban areas.

\section{Access to Health, Social Services and Household facilities}

From the analysis of The General Household Survey of 2005 (STATSSA 2006a) it is observed that access to health and social services (housing, sanitation, electricity, refuse removal, water and other amenities) has improved since 2002 for the general population.

The last 12 years after the first democratic elections have seen a rapid rise in the socioeconomic status of the previously disenfranchised in South Africa. Some of the factors that contributed to this rise include the expansion and improvement of access to social grants, and the expansion of the programme of extending basic household services to rural areas and informal settlements. This has not been the case for youth. Tables 1 and 2 give an indication of the proportion of youth who are able to access some of the above mentioned facilities.

Table 1 highlights that, firstly, most young people do not have access to basic household amenities, and secondly, there was no improvement in their access of basic amenities within the 5-year period of 1996 to 2001 as compiled from the Census 2001.

Table 2 shows the proportion of young people who had access to household goods in 2001. The proportion of young people, who had access to these goods, is lower than what

Table 1 Proportion of persons aged 14-35 years with access to piped water facilities: 1996 and 2001

\begin{tabular}{lllllllllr}
\hline Year & $\begin{array}{l}\text { Eastern } \\
\text { Cape }\end{array}$ & $\begin{array}{l}\text { Free } \\
\text { State }\end{array}$ & Gauteng & KwaZulu-Natal & Limpopo & Mpumalanga & $\begin{array}{l}\text { Northern } \\
\text { Cape }\end{array}$ & $\begin{array}{l}\text { North } \\
\text { West }\end{array}$ & $\begin{array}{l}\text { Western } \\
\text { Cape }\end{array}$ \\
\hline 1996 & 7.8 & 6.5 & 20.0 & 12.1 & 8.9 & 5.7 & 1.8 & 6.7 & 10.2 \\
2001 & 6.3 & 5.4 & 20.9 & 11.4 & 6.2 & 4.9 & 1.6 & 5.7 & 9.2 \\
\hline
\end{tabular}

Source: Macro Social Report, 2006 cited by Moleke 2006 
Table 2 Proportion of young people (aged 14-35) with access to household goods: 2001

Source: Status of the Youth Data 2003

\begin{tabular}{lc}
\hline Household goods & Percentage \\
\hline Radio & 74.8 \\
Television & 57.3 \\
Refrigerator & 53.8 \\
Cell-phone & 34.6 \\
Telephone & 22.7 \\
Computer & 7.5 \\
\hline
\end{tabular}

would be expected to be the case in the general population. In addition to relatively low ownership of household facilities by young people, the ownership is also unequally distributed amongst the young people of different racial groups.

\section{Youth Education}

As indicated earlier, over the past three decades educational opportunities have expanded massively to the benefit of African youth and women in general. However, while secondary school enrolment has increased for disadvantaged groups, little advancement has been made in reducing the number of young people with little or no education. It is these young people who are particularly vulnerable to unemployment and economic marginalisation.

The majority of young people aspire towards education but race and gender inequalities determine who continues to higher levels of education. In Table 3, it is shown that Black youth are more likely to cite financial reasons as the chief barrier to continuing their education than any other reason.

While school enrolment has expanded dramatically, quality, repetition of grades and dropping out of school, are three of the major challenges facing the education system. Africans finish school at later ages than any other race group because they start school

Table 3 Stated reasons by young people for not being at school

Source: Compiled from the Status of the Youth Data 2003

\begin{tabular}{lc}
\hline Reasons for not studying & Percentage \\
\hline I found a Job & 10.6 \\
Wanted independence & 11.5 \\
Save for further studies & 9.2 \\
Could not get the grades & 3.6 \\
Failed previous year & 20.9 \\
Parents wanted me to be independent & 2.8 \\
Parents could not afford payment & 4.2 \\
I could not afford payment & 38.3 \\
No need for further studies to get a job & 1.7 \\
To look after relatives & 2.1 \\
Got pregnant & 5.8 \\
Tired of studying & 1.8 \\
Completed my education goals & 6.6 \\
Illness prevented me from studying & 1.3 \\
\hline
\end{tabular}


later, experience interruptions during school and repeat grades more regularly (Biddecom and Bakilana 2003).

Public school enrolment rates, of Africans increased by 154\% between 1975 and 1994. In 2003, school attendance rate of 15-year olds stood at $96.6 \%$ (Department of Education 2006). The provincial spread of enrolment ranged from $94.1 \%$ in Northern Cape to $98.1 \%$ in Gauteng. Additionally, about half a million learners drop out of school each year between Grade 1 and Grade 11. Taking into account those who drop out of school and those who complete Grade 12 (either passed or failed), every year about a million young people arrive at the doorsteps of the labour market seeking employment, and only $29 \%$ of them would have completed secondary school education-this in a market that is looking for semi-skilled and skilled labour (Richter et al. 2005).

\subsection{Proportion of Young People Who Obtain Matric (Completion of Grade 12)}

In the post apartheid South Africa, there has been a dramatic increase in the number of young people among all races who get their matric certificate. In spite of this increase, the proportion of Africans and Coloureds has not increased substantially. Among Africans, the increase in proportion between 1995 and 2006 is a modest $4 \%$ for those who completed matric by age 25 (Department of Education 2006). Coloureds had a much bigger share of the increase, from $10 \%$ in the same age group during the same period, to an estimated 24.5\%. The Asian group had an even larger increase of young people who completed matric by age 25 . Over half of Asians completed matric by age 25 in the same period. Whites on the other hand, had the highest rate of matric passes, which is closer to threequarters by age 25 .

The above figures show that in-spite of a remarkable increase of young people obtaining matric certificates among all races, there are still wide gaps between Africans and Coloureds at the one end, and Whites and Indians on the other.

Therefore, in spite of the above mentioned improvements, there are serious challenges that need urgent attention. The first relates to the standard of South African education. An international study, which assessed performance of learners in Mathematics and Science found that South African average scores are lower than a number of African countries (Perry and Arendse 2003). The second issue relates to the number of learners who dropout from the education system. About half a million learners dropout of school between grade 1 and 11 every year (Richter et al. 2005).

Thirdly there is a serious issue of repetition of grades. On average, it takes learners 19.2 years to complete 12 years of schooling. About 179,000 matriculants fail matric every year. Furthermore, $50 \%$ of those who register for further and higher education dropout before getting a qualification (Richter et al. 2005).

Uneducated young people in South Africa are more likely to be either Africans or Coloureds, as shown in the Figs. 1 and 2. Furthermore, the racial profile of the uneducated remains the same in spite of gains in increasing school enrolments among Africans and Coloureds.

The enrolment rate at tertiary institutions has also increased dramatically in the last 12 years, especially for Africans. Currently, $60 \%$ of all students in the tertiary sector are Africans, 6\% Coloureds, 26\% whites and 8\% Indians. (Department of Education 2006). The number of females enrolled at tertiary institutions is higher than that of males. In the age cohort 19-24 years, tertiary education participation rates in the years 2002 to 2004 was $15 \%$ among Africans, with Whites having the highest enrolment rate of $34 \%$, Indians at $32 \%$ and Coloureds at a lowly $12 \%$ (DoE 2006). 


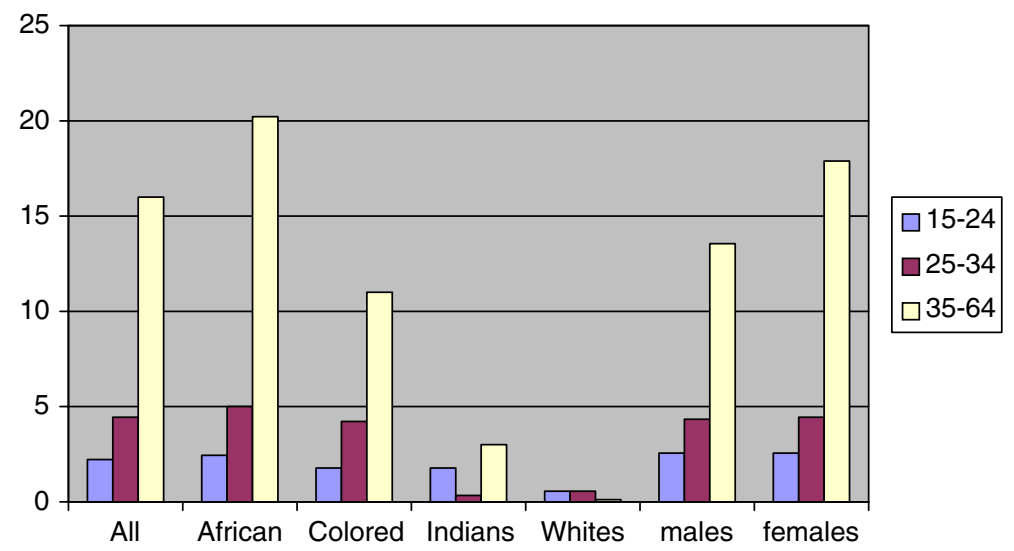

Fig. 1 Rate of illiteracy in South Africa, 2003. Source: IES/LFS2000, STATSSA: extracted from Richter et al. 2003

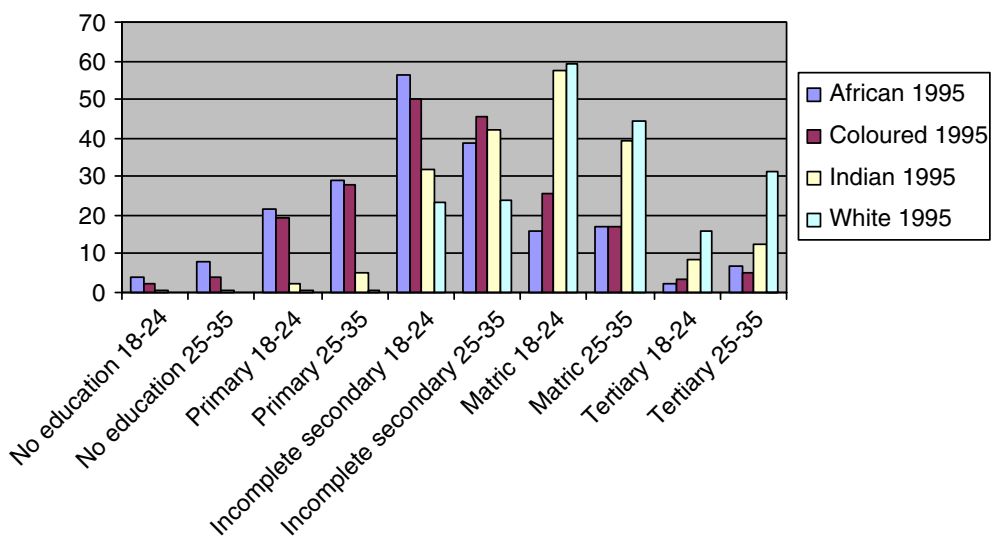

Fig. 2 Highest levels in education among youth by age as percentage of the population, 1995. Source: Status of the Youth Data 2003

Besides universities, Further Education and Training (FET) institutions have been established to give young people industrial skills as an alternative to academic pursuit. Although the government has been promoting these institutions as viable alternatives, participation rates are low, estimated at 2.7\% in 2002 (Department of Education 2006). FET institutions are generally highly gendered, with women mostly found in social services (92\%), while men favour engineering and other 'hard' fields (81\%) (DoE 2006).

\section{Youth Employment/Unemployment}

It is highly paradoxical that, although there is generally a linear relationship between the level of education and employment, since 1995 the largest growth in unemployment has been among those with matriculation and tertiary education. African graduates have been worst affected and this has been related to the fields of study chosen and perceptions around the quality of education gained from historically disadvantaged institutions. 
According to the literature, work is seldom seen only as a means by which an individual sustains life. It also has other dimensions, including economic, social and psychological. (Morrow et al. 2005). Research shows that unemployed people often experience feelings of low self-esteem resulting from not being involved in activities that are valued by other people (Morrow et al. 2005). The functions of work are therefore of great importance to both society and to the individual. Youth unemployment specifically has become a contentious issue. An estimate of the International Labour Office (ILO) in their World Employment Report (1998) indicated that at least 60 million young people were unemployed at that time and that youth unemployment rates could be as high as 3 times those of adults. The report estimates that between 1998 and 2010, 700 million young people will try to enter the labour market in developing countries (more than the entire labour force of the developed countries in 1990). The ILO projected that this required the creation of more than a billion jobs in order to give these new workers access to labour markets and to reduce unemployment. As McCord and Bhorat (2003), point out, South Africa's unemployment rates are higher than those of "most developing countries in Latin America or Asia, and significantly higher ... than those of the middle or higher-income countries". Unemployment has been steadily growing since the early 1970s, and in 2002 stood at $30.5 \%$ (4.8 million people using the strict definition) and $41.8 \%$ (using the expanded definition, which includes discouraged workers who are not actively seeking employment) (op lit). However, whether one uses the strict or expanded definition, the impact of such high levels of unemployment are acute, particularly when one takes into consideration the skewed distribution of unemployment among different segments of the population Fig. 3

Our study shows that young people are disproportionately affected by unemployment in South Africa. More than two thirds of youth between the ages of 18 and 35 years are unemployed. Young people with low levels of education, women, rural youth and African youth are worst affected. Unemployment has been linked to the inability of the economy to cope with the massive increase in the economically active population, particularly among women.

Table 4 shows that young people spend on average over a year looking for a job. When young people do find work, it is often temporary, poorly paid, under poor working conditions and with limited career prospects. At least a quarter of young people are employed in temporary positions and about two thirds work in the services sector. The Status of the Youth data shows a growing percentage of young people, particularly African and Coloured youth, work in the informal sector. This is in line a minimal percentage of young

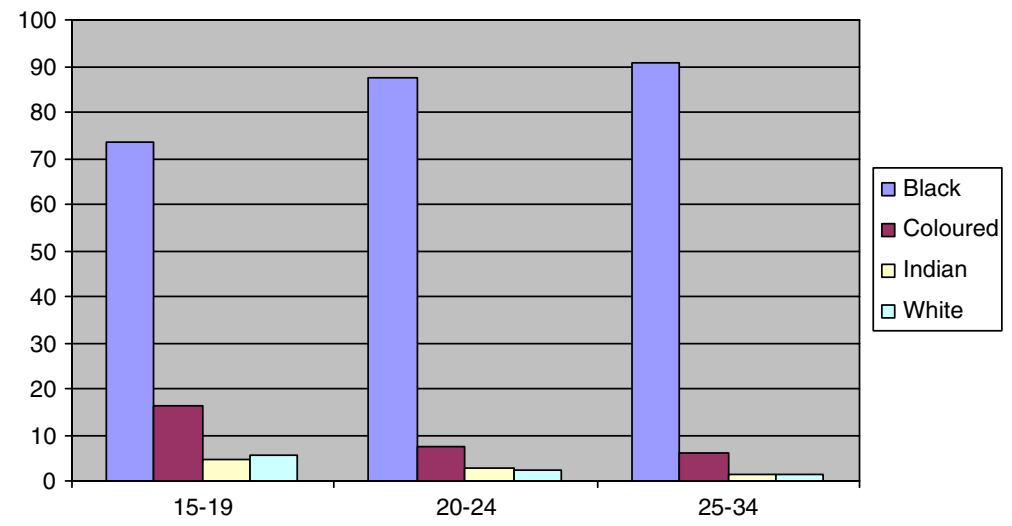

Fig. 3 Percentage of unemployment by age and race, 2002. Source: Status of the Youth Data 2003 
Table 4 Number of months young people look for work after completing studying by race

Source: Compiled from the Status of the Youth Data 2003

\begin{tabular}{lc}
\hline Race & No. of months \\
\hline African & 15.70 \\
Coloured & 14.87 \\
Indian & 8.02 \\
White & 12.44 \\
Total & 14.45 \\
\hline
\end{tabular}

people $(6 \%)$ found in the Status of the Youth data to be self-employed half of whom opted for this route because jobs were not available in the formal sector.

The number of people participating in the labour market has increased from 6 to 8.4 million since 1995 (Richter et al. 2005). Employment has only increased from 4.3 to 4.9 million, with the number of unemployed young people increasing from 1.7 to 3.5 million during the same period. Youth unemployment is estimated at about 33\%, 5.1\% of these having obtained tertiary education. Among tertiary education graduates, those most likely to be unemployed are likely to be those who have studied education, business, commerce and management studies, or health studies. The institutions from which the youth graduate also play a role in the employment status. Students from previously disadvantaged institutions are less likely to obtain employment than their more affluent counterparts. This is attributed to the quality or rather the perceived quality of the education obtained from such institutions, which is perceived to be inferior (Richter et al. 2005).

The few young people who obtain employment, are often aided by personal contacts or networks. Black students often do not obtain the amount of career guidance they need to make informed decisions about their career paths (Richter et al. 2005). The networks required to assist young people make choices with regard to education and business, are weak. Black students are most likely to drop mathematics and science which hinders their future progress. An estimated two thirds of young people work within the private sector, a fifth, work for government and a tenth for NGO's and community based organisations (CBO's). At least 1 in 20 young people works as a domestic worker, while many Coloureds and Africans often have their first employment in elementary jobs that don't require any qualifications (Richter et al. 2005).

\section{Youth Financial Independence}

From analysing SYR survey data, it is observed that males (38\%) were more financially self-supporting than females (34\%). Higher proportions of Indians and Whites (55 and $56 \%$ ) were financially self-supporting compared to Africans and Coloureds (33 and 37\% respectively). Significantly higher proportions of older youth (25-35) were financially more self-supporting than the younger youth (18-24) (58 and 21\% respectively). More metropolitan youth were more likely to be financially self-supporting (40\%) than urban youth $(37 \%)$, and rural youth $(32 \%)$.

\subsection{Poverty Among the Youth}

Data on youth poverty in South Africa is not as readily forthcoming as that on childhood poverty. The Status of the Youth data of 2003 shows that in year 2000 a third of young people in South Africa, were living in poverty with $16 \%$ classified as ultra poor. 
Findings from SYR survey reveal that almost three quarters (72\%) of respondents indicated growing up under circumstances of poverty where they could not afford to meet their basic needs. Higher rates of poverty were reported among 18-24-year olds (41\%) than among 25-35-year olds (29\%), linked to dependence on impoverished households. African youth are worst affected with $48 \%$ of 18-24-year olds and 35\% of 25-35-year olds of these were classified as poor. After children, 18-24-year olds reported the highest rate of poverty. Almost two-thirds of respondents (64\%) indicated that they could not support themselves financially and a similar percentage $(67.7 \%)$ indicated that they had never held a job. On analysis of census data it becomes clear that there has been little change in youth earnings in the period 1996 to 2001 (Richter et al. 2005).

Poverty can be classified into two categories, one in terms of monetary metric and the other in terms of unmet basic needs. According to the first definition, people living below a particular income level are classified as poor people. Using the second definition of poverty, one would be classified as poor if basic human needs were not met. Examples of basic needs include housing, water and energy for lighting, refuse removal facilities, and access to employment (Kalule-Sabiti et al. 2001). The two most common symptoms of youth poverty in Africa are illiteracy and youth unemployment (op lit). Rural areas in Africa epitomize this disadvantage as compared to their urban counterparts. Young people in rural areas are less likely to overcome poverty mainly due to poor education and lack of basic infrastructure. Young people often react to lack of opportunities in their areas by moving en masse to urban areas. Due to the fact that most of these young people lack skills that will enable them to be absorbed in the urban economy, they get confined to the margins of the city in informal settlements. The challenges faced by youth living in poverty in South Africa are diverse and some of these challenges are explored below.

\subsection{What Makes Youth More Vulnerable to Poverty Than Other Age Groups?}

Youth poverty is linked to overall poverty in society. About $40 \%$ of South Africans live in poverty. South Africa is also characterised by high-income disparities (Cantillon et al. 1997). It is also acknowledged that urban-rural location plays a key role in the distribution of poverty, as the majority of the poor are concentrated in rural areas. Young people are especially vulnerable to poverty. An estimated 17 million of children and youth under the age of 18 in South Africa are likely to be living in poverty. Youth poverty in South Africa, like child poverty, is passed on from one generation to another (Cantillon et al. 1997). Indeed, $72 \%$ of young people interviewed in the Status of the Youth data show that they were born under conditions of poverty. In the process of moving from childhood to youth, some (46\%) have improved their economic condition, while $36.1 \%$ reported that their condition has remained the same, and $17.6 \%$ reported that their condition has worsened. Thus, a significant portion of youth poverty is a legacy of childhood poverty (Richter et al. 2005).

Youth poverty, like childhood poverty is related to the fact that young people remain dependants for a long time. Factors contributing to this include the length of time taken to complete schooling, scarcity of jobs after completion of education and low wages associated with entry jobs for a significant number of young people. It is also common for young people in South Africa to be expected to send regular remittances to their ageing parents or to finance the education of younger siblings. Another cause for youth poverty is early childbearing, as shall be shown in the section on fertility below. This is especially the case among females who are most likely to become the main caregivers of those children. Youth poverty is also related to the residential patterns of young people. Most young 
people move away from their family of origin in search of economic opportunities. However, staying alone would economically disadvantage lowly paid young persons who do not benefit from economies of scale, offered by families of origin.

Rural poverty is often exacerbated by the poor health of young people, which is likely to be the result of malnutrition and HIV and AIDS. Prolonged morbidity necessitates expensive medication and reduces chances of being economically active. Rural areas, especially former homelands are poorly developed and often have poor service delivery. The fundamental problem of proper basic housing is yet to be addressed in many of these areas. These unmet basic needs cause an array of health and other socially related problems (Cantillon et al. 1997).

\subsection{Youth Migration and Poverty}

An analysis of the Status of the Youth Data shows that, while 54\% of male and 59\% of female respondents were born in rural areas, in 2003 only $39 \%$ of males and $45 \%$ of females respectively still resided in rural areas. Similar to national findings, the study shows that the highest net in-migration of young adults was in Gauteng, followed by the Western Cape, both provinces with higher economic potential.

Migration can be classified into two categories, that of migrants 'proper' and that of labour migrants. The difference between migration and labour migration is the motive for relocation. For instance labour migration is often used to identify the migrants that move in search of employment. Migrants 'proper' are those who move as family units, not all in search of work but rather in support of someone who has obtained employment. A labour migrant is often a single person (one person) who goes in search of employment. Migrant labourers decrease with increasing income whereas migration "proper" increases with the increase of income. The gender specifications differ for these two types of migration. Females are more inclined to migration 'proper' than labour migration, whereas their male counterparts are more likely to migrate for labour purposes. Different areas in the country would appeal differently to migrants 'proper' and labour migrants. The ones more likely to migrate for labour would migrate to areas such as Free State and KwaZulu Natal, whereas migrants 'proper' would move to Gauteng (because of mines) and Western Cape (because of wineries and farms) (Kok et al. 2003).

The greatest problem faced by youth in present day South Africa is that of unemployment as discussed earlier. Youth in South Africa are more likely to migrate in search of employment. The poverty and lack of employment in South Africa has created a rise in the number of youth who migrate. These youth often migrate from the impoverished parts of the country to the more prosperous areas, in search of employment. Gauteng is the province that many young people migrate to in the hope of obtaining employment. The level of skills that they have will affect the rate at which they obtain employment. Many of the young people who migrate are often unskilled and find it near impossible to obtain employment (Kalule-Sabiti et al. 2001).

It is more common for skilled migrant youth to obtain employment but these skilled youth remain few in number. The unskilled youth often face long periods of time without any form of employment (Kok et al. 2003). The lack of employment and family responsibilities often lead youth to engage in unlawful behaviour in order to survive. Lacking a family structure and having the need to belong, they are easily recruited into gangsterism. The young females find themselves in the sex trade industry. The main reason many of these young people resort to drastic measures to obtain money is that they often have dependents in the rural areas (Kalule-Sabiti et al. 2001). 


\subsection{Some Indicators of the Levels of Poverty Among Young People}

One indication of poverty among South African youth is the number of young people who drop out of school because of financial difficulties. As stated before, the Status of the Youth data reveals that, financial difficulties are the biggest reason for young people stopping their studies. About $38 \%$ of young people could not continue with their studies because of financial difficulties. A further $11.8 \%$ stopped studying because they wanted to get a job so as to save for further studies. This reflects how sheer poverty is a barrier to young people realizing their full potential in South Africa. A further indication of financial hardship experienced by young people is the proportion of young people who claim they never received financial help from their families while they were studying. About $19 \%$ of young people never received financial help from their families, ranging from $22 \%$ among Africans to $2.5 \%$ among Indians. According to Vally et al. (1998), schools themselves are usually an extension of home poverty as there is gross lack of infrastructure conducive to learning. Approximately one in four schools do not have any water and at least $57 \%$ of schools do not have electricity. The problem of poor sanitation is considerable with at least $52 \%$ of schools using pit toilets and $13 \%$ not having any toilet facilities at all (Vally et al. 1998).

Further, the Status of the Youth data set shows that after school, it is usually a long battle before a young person finds a job. The average period young people experience before finding a job is 14 months. Just less than a third (31\%) find jobs in the informal sector and this increase to many as $50 \%$ for rural young people getting their first jobs. A quarter of young people who have completed schooling start their working life on a parttime basis. This phenomenon is more widely spread in rural areas, where up to a third of young people who started work were part-time on their first job. Another indicator of poverty among young people is the long time young people remain dependents often of poor parents. Only $21.1 \%$ of young people in the ages 18 to 24 were able to support themselves, and just over $58 \%$ in the age group 25 to 35 .

\subsection{Levels of Youth Poverty in South Africa}

Poverty levels are higher among young people below 24 years of age than young people 24-35 years of age. As is the case in all age groups, poverty is higher among females than males, with gender disparity higher among younger youth. Poverty is mostly found among African and Coloured youth. As stated above, most of the poor youth reside in rural areas. Limpopo and Eastern Cape are provinces with the highest prevalence of poor young people, followed by the Free State and KwaZulu-Natal. On the other hand, more urbanized provinces like Gauteng and Western Cape have lower proportions of poorer young people. The SYR provided an estimation of the level of poverty among youth in South Africa as follows: the poverty line used in this study was set up at $20 \%$ per capita household expenditure (R1 305 in 2003) for the ultra poor and 40\% per capita household expenditure (R2 352 in 2003) for the poor. Using the above measures, approximately a third (34\%) of young people in South Africa are poor, and $16 \%$ are ultra poor (Richter et al. 2005).

\section{Youth Mortality and Health}

Young people have historically represented the healthiest sector of the population, but recent challenges, which include HIV/AIDS, substance abuse, mental ill health, and crime and violence (to be published in a separate article) are compromising this advantage. 
Of all the health conditions associated with young people, HIV/AIDS is the most critical. HIV/AIDS is of importance not only because young people are most vulnerable to infection, but also because there is growing consensus that the best way to halt the spread of AIDS is to focus on youth and to prevent new infections (UNAIDS 2002). It is estimated that more than 60 million people around the world have been infected with HIV/AIDS and that 20 million of those people have already died (Shisana et al. 2002). In general, it has been shown that in communities with high sero-prevalence rates most new HIV infections occur during adolescence (Leclere-Madlala 2002, p. 21). Abt associates estimated in 2001 that over $60 \%$ of HIV infections in South Africa occurred before the age of 25 years (Leclere-Madlala 2002, p. 21), and an extensive international study of HIV/AIDS and youth maintains that more than half of those newly infected with HIV today are between 15 and 24 years old (UNAIDS 2002, p. 5).

There is little doubt that HIV is the biggest health challenge currently facing young people in South Africa. Antenatal survey data shows that HIV prevalence has increased among pregnant women from $0.7 \%$ in 1990 to $30.2 \%$ in 2005 (Department of Health 2006). HIV prevalence is generally high in the 20 to 34-year age band and peaks among 25-29-year old pregnant women at 39.5\%. However, indications are that behaviour is starting to change with $50 \%$ of young people reporting increased condom use (SYR Data). Although knowing one's HIV status increases the adoption of preventative behaviours, only a third of young people have had an HIV test and a smaller percentage return to receive their results.

Human mortality, like morbidity, has been historically higher at early and later stages of life, and lowest during early adult life. Causes of mortality can be divided into two, namely natural causes, which are a result of disease or old age, and unnatural causes which are caused by injury or human intervention. In most societies youth population is characterised by low natural mortality and relatively high unnatural mortality due to risky behaviour. Before the AIDS pandemic, adult mortality including that of young people was generally on the decline in South Africa but there is currently a reversal of the trend (Cantillon et al. 1997).

\subsection{Mortality Rates}

Figure 4 shows youth mortality from age group 15-19 to 30-34 for both males and females. The first observation is that mortality rate is lowest for the age-group 15-19, rising in subsequent years up to the ages 30-34. Secondly, the youth mortality rate has increased drastically from the year 1997 to 2004, with the exception, of 15-19 age group. In 1997, female youth had a lower mortality rate than males, but the gender profile of youth mortality had reversed by the year 2004. This reversal of gender patterns of mortality is higher at younger ages. The gender disparity in mortality is higher among lower age groups, reaching near parity in the age group 30-34, as male mortality rate catches up in later years.

\subsubsection{Unnatural Deaths}

Unnatural mortality in South Africa (Fig. 5) declined marginally between 1997 and 2004. Male unnatural death rates are considerably higher than that of females, as it is in most parts of the world. Unnatural death among adult female youth is almost constant from the age of 20 up to age 64 . On the other hand, male unnatural deaths are higher among the 


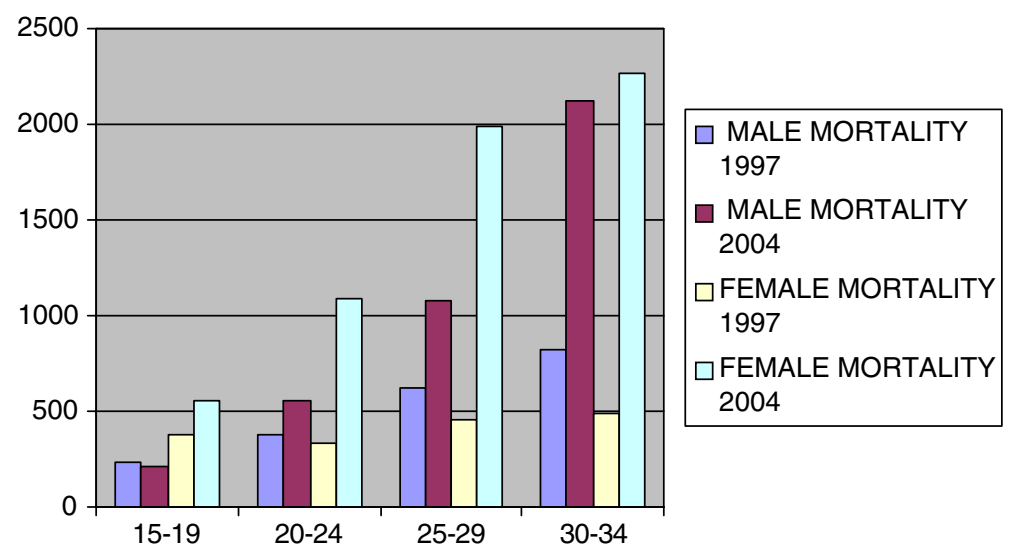

Fig. 4 Distribution of youth mortality by sex and age-group 1997-2004. Source: STATSSA 2006b

youth than at any stage of their adult life. This is associated with young males being more inclined to risky behaviour. Some of the unnatural deaths are due to high suicide rate among young people. Every year more than 10,000 young people commit suicide with rates peaking in the 20 to 34-year age group (Morrow et al. 2005). The unnatural death rate has on the overall declined for the period 1997 to 2004, except for the age group 20-24, which has seen an increase in both sexes. Reasons for this increase are not known.

\subsubsection{Natural Deaths}

Teenage natural mortality has remained low and constant over the period 1997-2004 (Fig. 6). In contrast, youth past teenage stage have seen a drastic increase in natural mortality, rising with the increase in age up to age 34 . Youth natural mortality has been higher among females than among males. The natural mortality has been increasing over the 8-year period, with the increase being higher in the 30-34-age group. As a result this age group has the highest natural mortality rate in the adult ages of 15-64-year age group.

As stated above, overall mortality has increased among the youth as a result of an increase in natural mortality among young people, with females having higher mortality rates. Unnatural youth mortality rates have declined marginally among young people. It is noteworthy that young people in 1994 were more likely to die of unnatural causes, whereas by 2004 a young person is more likely to die of natural causes.

\section{Youth Fertility}

\subsection{Sexual Initiation in South Africa}

There is a general agreement that the teenage years in South Africa are characterised by socially sanctioned freedom and sexual experimentation for both genders, more so, for young men (Makiwane 1998). While marriage in South Africa is relatively late, pre-marital sexual activity is common and has become accepted through its very prevalence (Makiwane 1998). 


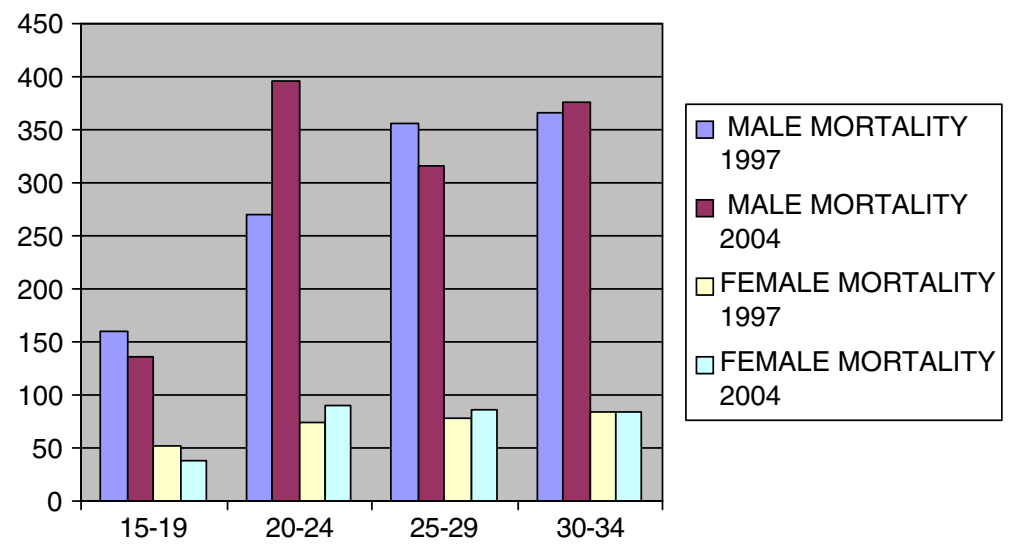

Fig. 5 Distribution of unnatural youth mortality by sex and age group. Source: STATSSA 2006b

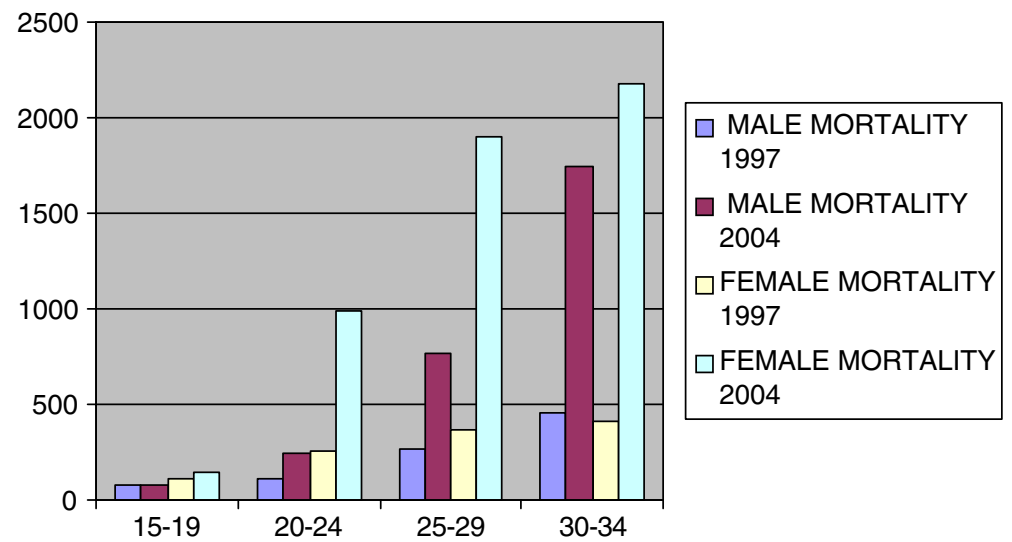

Fig. 6 The distribution of natural youth mortality by sex and age group 1997-2004. Source: STATSSA $2006 b$

One of the indications of high sexual activity among young people is the low age at sexual debut. The Status of the Youth Survey shows that the median age at sexual debut or first sex is 16 years for males and 17 years for females between aged 18 and 24 . The mean age of sexual debut in this age group is 16 years for Africans; 16.06 years for Whites, 16.27 for Coloureds and 17.25 for Indians. The median age of first sex among respondents aged 25 to 35 years across both sexes is 18 years. A similar trend towards earlier sexual debut among younger respondents has been noted in the Nelson Mandela/HSRC Study of HIV/AIDS (Shisana et al. 2002). This trend is also reflected in the Status of the Youth study, which shows sexual debut by race with Africans having the youngest median age of sexual debut at 16 years followed by Whites and Coloureds at 17 years and Indians at 19 years. Among the youth between age 18 and 24, 60.2\% of Africans, 47.8\% of Whites, $46.8 \%$ of Coloureds and $30.8 \%$ of Indians were sexually experienced. Among 25 to 35 -year olds, however, the median age of first sex is 18 years for African and White respondents and 19 years for Coloureds and Indians. This indicates that the age at sex 
debut has been declining recently. Another indication of a rapidly declining age at sex debut in South Africa is relatively low mean ages of sex debut for people aged 15-49, compared to that of youth.

\subsection{Contraceptive Use}

Status of the Youth data show a total of $48.8 \%$ of young people claim to have used some form of contraception at first sex. Of these respondents, $42.5 \%$ used a condom. The comparison between 18 to 24-year olds and 25 to 35-year olds shows that contraceptive and condom use, as well as other forms of contraception at first sex, has increased overall among younger respondents aged 18 to 24-years. Contraceptive and condom use are highest among White females and lowest among White males in the 18 to 24 year age group. While the same use is more or less evenly distributed across gender for the African, Coloured and Indian groups, with men reporting slightly higher use. Although we see a trend of increase in the use of condoms among all race groups in South Africa, it should be noted that about half of sexually experienced young people report that they did not use condoms during their first sexual intercourse. The use of condoms is considerably higher among Whites and Indians and lower among Africans and Coloureds.

Although the use of condoms is relatively high, there are indications that it is not consistently used in every sexual encounter. The South African Demographic and Health Survey (1998) showed that while $68 \%$ of adult respondents claimed that they used contraception in their last sexual encounter, only $17.3 \%$ had used condoms.

\subsection{Pregnancy}

Analysis of data from the status of the youth study shows that $32 \%$ of young people between ages 16-35 have been pregnant or have made someone pregnant. Just over a quarter of African female respondents aged 18 to 24 years have fallen pregnant. Of those who have been pregnant, $70 \%$ say the pregnancy was unplanned. Africans have the highest rate of unplanned pregnancies in the 18 to 24 years age cohort.

\subsection{Trends in Youth Fertility}

This section describes trends in fertility of young people in South Africa. The fertility trends were compiled from the October Household Surveys 1995 and 1998, the Demographic and Health Survey 1998 and the Census data 2001. The Relational Gompertz Model was used to estimate age-specific fertility rates (see Makiwane and Udjo 2006).

Generally, South African fertility patterns differ remarkably among different race groups. Fertility levels of whites mirror fertility trends in more developed countries where the transition from high to low fertility has been completed. The Indian and Coloured population is near completion of the fertility transition. Although fertility levels of Africans have been higher than other population groups, they have recently experienced the highest rate of fertility decline. It is with this background that the age-specific fertility rates of different population groups are examined below (see Figs. 7 and 8).

Figures 7 and 8 below show the estimated trend in relative age-specific fertility rates of Africans and Whites respectively. Note that total fertility rates in South Africa have been declining in the past few decades (see Chimere-Dan 1993, for example). Udjo (2003) estimated that the total fertility rate in South Africa declined from about 4.9 in 1970 to about 3.2 in 1998. 


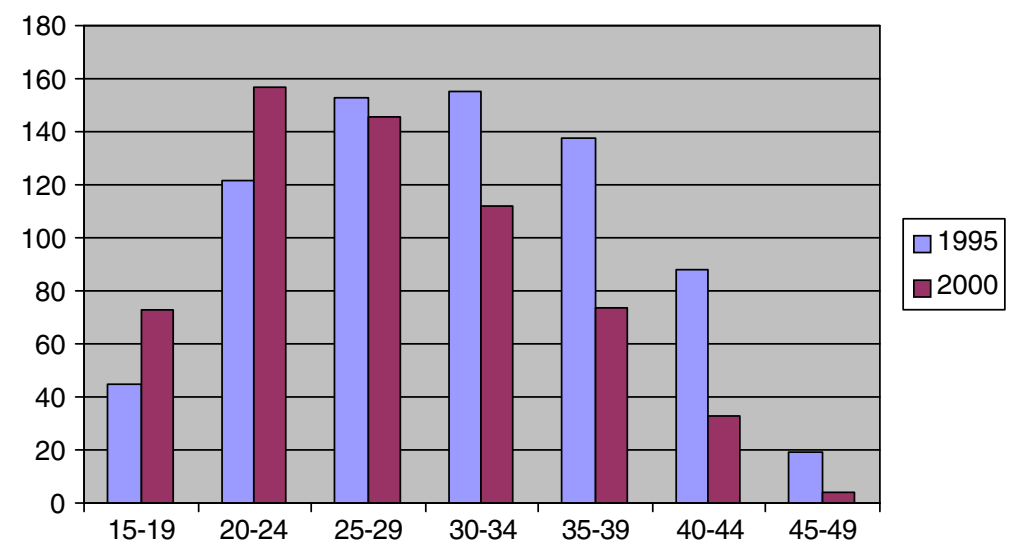

Fig. 7 Age specific fertility rate for the African population 1995-2000. Source: Makiwane and Udjo (2006)

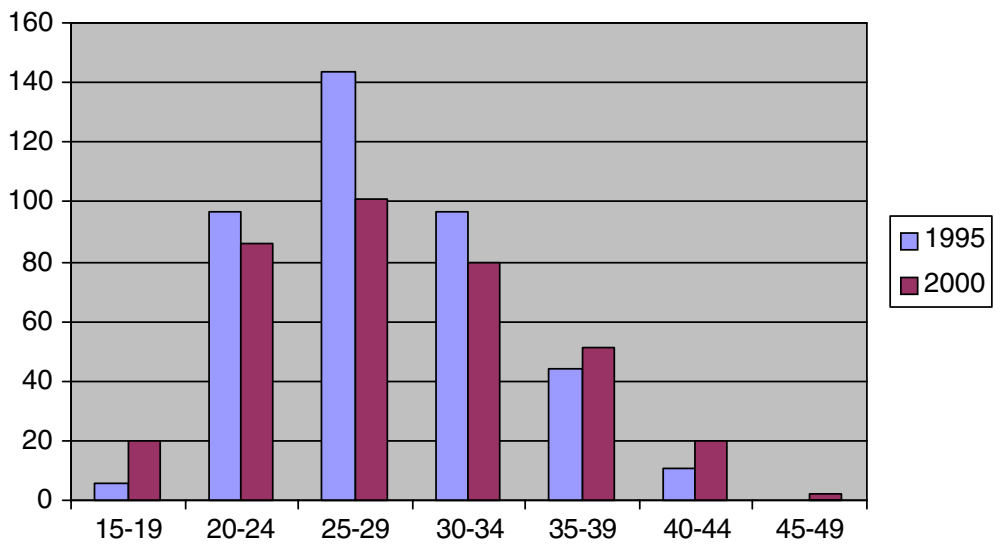

Fig. 8 Age-specific fertility rate for the White population. Source: Makiwane and Udjo (2006)

The two figures above show age-specific fertility rate among Africans and Whites. The most evident trend in the African population is the major shift of fertility towards young people. While there have been a decline in fertility in the ages 25 upwards, the reverse has happened among women younger than 25 , who show a significant increase in fertility.

It is noteworthy that in spite of the total fertility rate being low and relatively stable amongst Whites; significant shifts towards teenage fertility have also been observed.

The rising share of births to young women is visible in most countries of the world. The general trend, worldwide, is that where fertility rates drop, the share of births to young women is among the highest. In line with this trend, as the rate of fertility in South Africa declines, so the rate of fertility among young women is increasing.

\section{Youth Quality of Life Levels}

Against the backdrop of the social economic factors discussed above, it is of interest to analyse young people's satisfaction with life in general. The findings are most interesting, 
Table 5 Measures of quality of life by race

\begin{tabular}{cllll}
\hline & & Mean & Lower bound & Upper bound \\
\hline How satisfied are you with your & African & 3.13 & 3.06 & 3.21 \\
life as a whole these days? ${ }^{\mathrm{a}}$ & Coloured & 2.62 & 2.48 & 2.76 \\
& Indian & 2.20 & 2.02 & 2.38 \\
& White & 2.18 & 2.01 & 2.34 \\
& Total & 2.93 & 2.87 & 2.99 \\
Living standard measure $^{\text {b }}$ & African & 1.72 & 1.67 & 1.76 \\
& Coloured & 2.28 & 2.19 & 2.37 \\
& Indian & 2.86 & 2.78 & 2.93 \\
& White & 2.96 & 2.91 & 3.01 \\
Taking all things together, & Total & 1.96 & 1.92 & 2.00 \\
how pappy are you? $^{c}$ & African & 2.84 & 2.77 & 2.91 \\
& Coloured & 2.34 & 2.21 & 2.48 \\
& Indian & 2.10 & 1.94 & 2.27 \\
& White & 1.92 & 1.74 & 2.09 \\
& Total & 2.66 & 2.60 & 2.72
\end{tabular}

Source: Compiled from the South African Social Attitude Survey 2007

a Quality of life levels in this study were determined using three measures, which were answers to the following questions; "Taking all things together, how happy are you?" The scaling of the answer ranges from 1 for very happy young persons, to 5 for very unhappy

b The second question asks "How satisfied are you with your life these days?" The answers to the question ranges from one (very satisfied) to five very unsatisfied

${ }^{c}$ Living standard measure gives a score for number goods and services young people have in their household. The score ranges from ten for a young person staying in a household with most goods and services, and therefore living a comfortable lifestyle, to 1 on the opposite side of the scale

and as Møller (2007) has shown, the level of satisfaction of life in South Africa coincides with racial disparities in the standard of living.

The responses to the first question on happiness from the South African Social Attitudes Survey (SASSAS) differ significantly according to race. Whites report a fairly high degree of happiness (1.92), which is not significantly different to that of Indians at 2.10. Africans reported a low level of happiness (2.84), followed by Coloureds at 2.34 (Table 5). Whites have also the highest level of life satisfaction (2.18) Africans have the lowest at (3.13). Similarly, the Living Standard Measure follow the same trend, with Whites and Indian youth having a score of 2.96 and 2.86 respectively, Coloureds and Africans scoring a lowly 2.28, 1.72 respectively (Table 5). It must be said, though, that the Living Standard Measure among South African youth is considerable lower than that of the general population.

\section{Summary}

Political changes that swept the country in the mid nineties brought visible advancement to young people in South Africa, as evidenced by a dramatic increase in the enrolment of young people in the education system, and increase in number of young people joining the labour force. In spite of this impressive gain, serious problem of quality of education and drop out rate have led to a large section of the population remaining outside the labour market. In addition, the AIDS epidemic, which swept the country at the same time when 
political changes were taking place, resulted in increase in morbidity and mortality among young people. As a result, the quality of life among majority of young people remains low, reflecting the historical racial cleavages of South African society.

Open Access This article is distributed under the terms of the Creative Commons Attribution Noncommercial License which permits any noncommercial use, distribution, and reproduction in any medium, provided the original author(s) and source are credited.

\section{References}

Biddecom, A. E., \& Bakilana, A. (2003). Transitions into sex. Cape Town: University of Cape Town, Parenthood and Unions among Adolescents and Young Adults in South Africa.

Cantillon, B., Marx, I., \& Van den Bosch, K. (1997). The challenge of poverty and social exclusion. In OECD, family, market and community: Equity and efficiency in social policy, Paris: OECDE.

Chimere-Dan, O. (1993). Racial patterns of fertility decline in South Africa. In International union for the scientific study of population (pp. 43-51). International Population Conference, Montreal, Liege.

Department of Health. (2006). National HIV and syphilis antenatal sero-prevalence survey in South Africa 2005. Pretoria: Department of Health.

Department of Education (DoE). (2006). Monitoring and evaluation report on the impact and outcomes of the education system on South Africa's population: Evidence from household surveys. Pretoria.

International Labour Office. (1998). World Employment Report. 1998-1999 Employability in the global economy-how training matters.

Kalule-Sabiti, I., Kahimbaara, J. A., \& Chimere-Dan, O. (2001). Youth migration and poverty in the Western Province. The Population Training and Research Unit University of North West: A Poverty Alleviation Research Report.

Kok, P., Donovan, O. M., Bouare, O., \& van Zyl, J. (2003). Post-apartheid patterns on internal migration in South Africa. HSRC Publishers.

Leclere-Madlala, S. (2002). Youth, HIV/AIDS and the impotence of sexual culture and context. Social Dynamics, 28(1), 20-41.

Makiwane, M. B. (1998). Adolescent pregnancy and reproductive health in Transkei (rural South Africa). African Journal of Reproductive Health, 2, 41-48.

Makiwane, M., \& Udjo, E. (2006). A quantitative Study on fertility trends in South Africa, and their relationship with introduction of child support grant. A report prepared for the Department of Social Development, Pretoria.

McCord, A., \& Bhorat, H. (2003). Employment and labour market trends in South Africa. In A. Kraak \& H. Perold (Eds.), Human resource development review. Education, employment and skills in South Africa (pp. 112-141). Pretoria: Human Sciences Research Council.

Moleke, P. (2006). The State of the Youth Development in 2006. A Mid-Term Review Discussion Document. Commissioned by the Youth Desk in the Presidency. Pretoria.

Møller, V. (2007). Social indicators research (Vol. 81, No 2.). pp. 181-201(21).

Morrow, S., Panday, S., \& Richter, L. (2005). Where we're at and where we're going: Young people in South Africa in 2005. Johannesburg: Umsobomvu Youth Fund.

Perry, H., \& Arendse, F. (2003). Public school education. In A. Kraak \& H. Perold (Eds.), Human resources development review. Education, employment and skills in South Africa (pp. 302-325). Pretoria: Human Sciences Research Council.

Richter, L., Emmet, T. Makiwane, M., du Toit, R., Brookes, H., Potgieter, C., Altman, M., \& Makhura, P. (2005). Status of the youth report: Produced on commission to the Umsobomvu Youth Fund, by the Child, Youth and Family.

Shisana, O., Simbayi, L., et al. (2002). Nelson Mandela/HSRC study of HIV/AIDS. South African National HIV prevalence, behavioural risks and mass.

STATSSA. (2006a). General household survey July 2005. Pretoria.

STATSSA. (2006b). Adult mortality (age 15-64) based on death notification data in South Africa: 19972004.

Udjo, E. (2003). A re-examination of levels and differentials in fertility in South Africa from recent evidence. Journal of Biosocial Science, 35, 413-431. doi:10.1017/S0021932003004139.

UNAIDS. (2002). Young people and HIV/AIDS: Opportunity in crisis. Geneva. 
Vally, S., Chisholm, L., \& Motala, S., (1998). Poverty and education in South Africa. SANGOCO publication Series No. 8

World Bank (2006). Development and the next generation. World Development Report 2007. Washington DC: World Bank. 